\title{
Nontraditional Study Abroad Destinations: Analysis of a Trend
}

\author{
R y a n W e I I s \\ University of Iowa
}

\section{Introd u c t i o n ${ }^{1}$}

The most recent data concerning education abroad, in addition to recording the largest number of US college students ever participating, shows that the selection of nontraditional destinations is increasing (Institute of International Education, 2004). ${ }^{2}$ As higher education institutions and study abroad providers offer students more options for studying in the African, Asian, Latin American, and Middle Eastern regions, students are responding in a positive way. ${ }^{3}$ Because of increased student interest, institutions are offering more of these programs, and a mutually reinforcing cycle has appeared. Is this move toward nontraditional destinations altogether positive? Is this trend helping to achieve the goals inherent in study abroad, or is it a detriment to them? This paper examines current literature, policy, and theory, and creates a framework for analyzing the personal, societal, and institutional rationales for education abroad in nontraditional locations. I conclude with policy and research implications based on the analysis, including a specific call for more empirical research into the outcomes and impacts of nontraditional study abroad destinations.

\section{Nontraditional Study Abroad Destinations- Where are They?}

Study abroad may be defined broadly as "the international movement of students and scholars" (Harari, 1992, p. 69). US education abroad, for these purposes, includes short- and long-term programs, exchange programs, service learning abroad, internships, and all other program types in which students from the US fulfill part of their education by traveling to a foreign country. Study abroad participation has steadily increased in recent years, with a record number of US students (nearly 175,000) participating in 2002-2003 (Institute of International Education, 2004).

Among these students, an increasing number traveled to what are commonly referred to as nontraditional destinations. The definition of "nontraditional" is slippery and may change depending on the context in which it is used. 
The primary criterion for being categorized as a nontraditional country is the fact that relatively few American students study there. This general definition is sometimes combined with the qualification of being non-European or nonEnglish speaking. Others classify non-industrial, third-world, or developing countries as nontraditional destinations. ${ }^{4}$ To strike a balance between accuracy, utility, and ease of definition, I will refer to nontraditional study abroad destinations simply as those in Africa, Asia, Latin America, or the Middle East. ${ }^{5}$

Europe has clearly been the most "traditional" destination since the inception of education abroad. For the last 15 years, Europe has annually hosted from $63-80 \%$ of the total number of US students abroad (Institute of International Education, 2004). Although its domination has waned in recent years, Europe still attracted approximately $63 \%$ of US students abroad in 2002-2003 (IIE, 2004). The United Kingdom, Italy, Spain, France, Germany, and Ireland were all "top-ten" destinations in 2002-2003, and accounted for about $53 \%$ of all US study abroad students (IIE, 2004). ${ }^{6}$

Although continuing to form a minority of the destinations selected by American students, nontraditional locations have seen a steady increase over the last 15 years (see Figure 1). All non-European regions of the world have gained in participation numbers, with the exception of the Middle East. The most recent data shows the largest nontraditional gains since 2001-2002 for Latin America (up 14\%) (IIE, 2004). ${ }^{7}$ One notable decrease in 2002-2003 was in Asia, due

Figure 1: Trends in Nontraditional Study Abroad Destination Enrollments

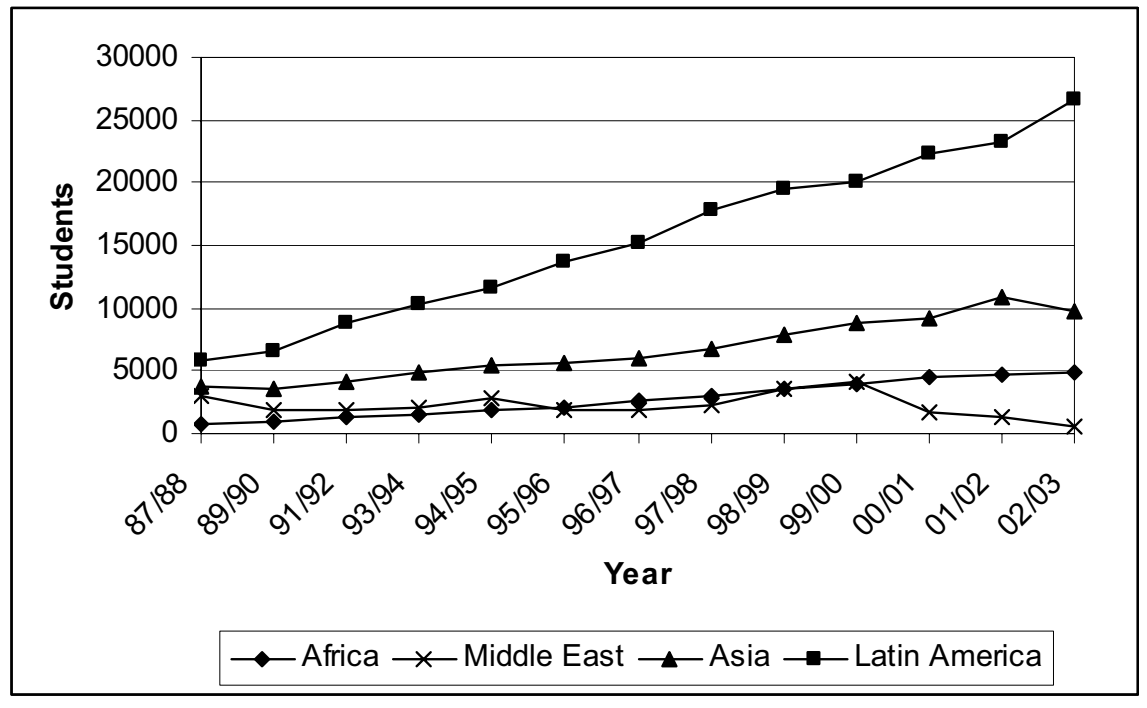


largely to the scare of SARS in China and surrounding countries. Even with a $36 \%$ decrease however, China remained the 12th most popular destination for US students abroad. Other nontraditional destinations placing within the top 20 most popular included Mexico, Costa Rica, Japan, Chile, Ecuador, South Africa, and Russia (IIE, 2004).

The trend toward greater participation in nontraditional study abroad destinations is not a new phenomenon. The 2002-2003 data could be reported much the same as they were five years earlier: "statistics show that the proportion of Americans going to countries that traditionally have not seen large contingents of U. S. students is growing steadily" (Desruisseaux, 1999, p. A60). Even earlier in the 90s, both educational and popular publications were reporting this trend (Rubin, 1995; Saltzman \& Mulrine, 1996).

Some study abroad professionals extol the virtues of expanding study abroad participation, and the increases in nontraditional destinations specifically, as a positive phenomenon. Others claim that the recent gains in participation are not sufficient, and that the trend toward nontraditional destinations should be further developed. Is this wise? Is the growing popularity of nontraditional destinations something to be encouraged as furthering the aims of international education? Or is this increased popularity abroad an insignificant trend with little academic basis or theoretical rationale? What follows is information to help answer these questions.

\section{Nontraditional Study Abroad Locations and the Literature}

The literature concerning nontraditional destinations in the arena of study abroad is sparse. Studies with the express purpose of examining the impacts of studying abroad nontraditional versus traditional locations are virtually nonexistent. The little evidence that is available comes from two main sources: studies of specific programs in one given nontraditional country, or research primarily concerning other study abroad factors that happen to include program location as a variable.

Research conducted about study abroad programs to nontraditional locations has most often been for a specific program in a specific country. These studies are inadequate for two reasons. First, a significant portion of them simply describes program activities and implementation, and does not explicitly study outcomes and impacts on students. Studies including the impacts on institutions or on society are even less common. In addition, single-country studies, even when they include high-quality data concerning student-level impacts, lack the information necessary to draw conclusions in comparison to traditional 
locations. Nevertheless, taken as a group, studies such as these may help in some small way to inform the discussion concerning the value of studying abroad in nontraditional locations. A few varied examples of study abroad research about nontraditional locations include Nepal (Farrell \& Suvedi, 2003), Zimbabwe (Elkin, 1998), and Japan (Mizuno, 1999). Research concerning study abroad, work abroad, or internships abroad in nontraditional countries has also been conducted for specific academic disciplines. Research from the nursing field, as one example, has been conducted in Thailand (Inglis, Rolls, \& Kristy, 1998) and Mexico (Bond \& Jones, 1994).

Study abroad research has rarely included nontraditional versus traditional location as a main focus. Studies have most often focused on other factors such as duration of stay, living arrangement, or type of classroom experience. However, some of these have at least included location as a contributing factor in their research design. The GLOSSARI Project, a study which examines learning outcomes for study abroad students, proposes to examine the correlation of learning outcomes with various factors, one of which is program location (Sutton $\&$ Rubin, 2004). Such studies may allow for a limited analysis of the findings concerning nontraditional destinations.

In an earlier study that examined student expectations of study abroad and corresponding factors that contributed to violating those expectations, "location of sojourn \& gender had the greatest effects on the expectancy violations scores, with location contributing to violation of coursework, climate, \& language use expectations" (Martin, Bradford, \& Rohrlich, 1995, p. 87). These results suggest that for research concerning cultural difference by location, student expectations must be considered. This is especially important for nontraditional destinations because student expectations are often quite different from the discovered reality. In a related study, researchers associated pre-departure concerns and expectations with the destination of the student (Martin \& Rohrlich, 1991).

Research that examines sojourn experiences and the reentry adjustments of participants has found that the location of the program has a significant influence (Rohrlich \& Martin, 1991), although the study did not include nontraditional locations. More recent research reported that location was one of several factors that were significant when examining personal growth and program satisfaction outcomes (Cook, 2004). This particular study found that higher satisfaction was reported for Eastern European and Latin American destinations in comparison to other regions. Additional research has examined study abroad factors that affect professional growth and personal development, and has reported that nontraditional locations impacted these outcomes posi- 
tively (Hutchins, 1996). Nearly ten years ago this author reported a concern for future research concerning the impact of destination choice: "Implications and recommendations for international education overseas study tours include further research into study tours abroad to understand the impact of geographic locations." (Hutchins, 1996, p. iii) To date, this call has largely gone unanswered.

The Georgetown University Consortium Project is one of a few research studies that explicitly asks questions pertaining to nontraditional destinations. Utilizing a US Department of Education Title VI grant, this research group examined several outcomes of study abroad. The group is focusing on research questions pertaining to, among other topics, differences in second-language oral proficiency between traditional and nontraditional locations, and differences in intercultural proficiency in developed vs. non-developed countries, as well as English-speaking vs. non-English-speaking countries (Vande Berg, Balkcum, Scheid, \& Whalen, 2004). These questions are aimed, in part, at measuring the impact of nontraditional study abroad destinations.

Although research on nontraditional locations has recently garnered some limited attention, past studies leave a significant gap in knowledge related to the impact of these destinations. Studies that do exist are often not generalizeable beyond one country, or do not report detailed findings relating to location. In addition, some studies report associations to student attitudes, expectations, and/or satisfaction. Although useful, these factors do not assist in assessing more complex outcomes related to students, institutions, and societies. In order to close the existing gap and explore this question further, I present a framework of related literature and current educational policy in order to illuminate the rationales behind study abroad. I then overlay the construct of nontraditional destinations onto this framework to determine the worth of the current trend of the increased popularity of non-traditional locations

\section{Rationales for Study Abroad: Three Levels}

Throughout the development and growth of education abroad, educators and policy makers have made many claims about these programs. The claims are based on rationales concerning the benefits of education abroad. The expression of these rationales is most often in the form of institutional and organizational goals. As such, this paper will refer to goals and rationales, with the understanding that organizational goals are simply the outward manifestation of an underlying belief system which contains specific justifications for the implementation of study abroad. 
Rationales for study abroad are neither simple nor homogenous, and may even be in conflict. A categorization framework is necessary in order to analyze these rationales. Schechter (1993) has grouped internationalization rationales into three main areas: pragmatic justifications, such as economic benefits, job preparation, or institutional competitiveness; liberal and liberating rationales, such as opening students' minds and providing a breadth of learning opportunities; and civic education purposes such that students can make "educated and ethical decisions about the principles of governance" (Schechter, 1993, p. 136). Knight (2004) presents a more thorough collection of rationales for international education, and she categorizes them as socio-cultural, political, economic, or academic. ${ }^{8}$

In order to utilize the most valuable items from previous systems, I present a partial, but representative list of the rationales that are used today for study abroad at three levels: student, society, and institution. These are not mutually exclusive categories, but are useful for demonstrative purposes nonetheless. Following this section, the same framework will be used specifically to analyze the nontraditional destination trend in study abroad.

The rationales most often put forward in favor of education abroad pertain to the intangible benefits that the individual will receive. The student will become more globally aware, or gain "global literacy," which is defined as "having a global consciousness and a critical understanding of how national and international issues intersect" (Biddle, 2002, p. 5). This general concept can be expanded with descriptions of students' personal growth, such as "worldmindedness" (Sampson \& Smith, 1957) and "openness to diversity." This factor has been shown to increase when students are exposed to diversity experiences in college (Pascarella, 2001).

Another student-centered justification for study abroad is better preparation for the modern workforce and a more competitive position in gaining employment (Knight, 2004). Employers today are looking for a competitive edge in the form of human capital, as well as social and cultural capital (Bourdieu, 1985; Coleman, 1988), on a global scale. Foreign language proficiency is one example of a skill developed during study abroad that may benefit students in employment. ${ }^{9}$ A more comprehensive term for the combination of various forms of capital that may be attained by students, including language, cultural, and technical skills, is "transnational competence" (Hawkins \& Cummings, 2000). Students themselves are claiming a job-related justification for study abroad. In a recent survey, over $80 \%$ of student respondents stated that knowledge of global issues, cultures, and customs "would be necessary to compete successfully in the job market" (Siaya \& Hayward, 2003, p. 9). 
At the next level of analysis, society, the goals described are in the public interest. However, many of the student-centered rationales listed above may be generally restated on a societal level. In the student-society relationship, international education provides the student with "new skills and knowledge of other cultures" which "fosters international understanding" and in turn "contributes to peaceful cooperation between nations" (Council on International Educational Exchange, 2004, para. 1).

International education often claims the promotion of intercultural understanding, citizenship development, and socio-cultural development as further benefits (Knight, 2004). Societal rationales "include world peace, national security, political and economic competition, and international cooperation" (Schoorman, 2000, p. 6). Schoorman (2000) observes that international education "efforts have been undertaken for reasons as divergent as the competitiveness of the 'Cold War' or 'Star Wars,' and images of the cooperation and interdependence of the 'global village'” (p. 6). With global interdependency as the normative viewpoint, a number of new rationales have also arisen promoting greater understanding in the global political, environmental, and social arenas (Racette, 1996). Theoretically, a greater societal understanding of other cultures will allow the United States to understand better global issues such as terrorism, peace-keeping, global pollution, and global migration.

Economic justifications also exist at a societal level: if our graduates are prepared with the skills to function effectively in the global economy, our country will be prepared for international competition as well. Mestenhauser refers to study abroad's current climate: "The present period is dominated by the metaphor of educational exchanges as export articles, and by the paradigm that international education enhances national competitiveness and provides strategic advantages" (1998; p. 49).

At the institutional level of analysis for study abroad rationales, colleges and universities posit the expanded learning that may occur via an international experience as a justification. Commonly touted academic goals include increased language skills, communication skills, and global knowledge. However, other, more complex benefits are also claimed. Schoorman (2000) sees international education activities as "counter-hegemonic" and cites the invaluable learning that can take place in such a climate. ${ }^{10}$ "Ironically, few educators have highlighted the pedagogical reason for internationalization: the intellectual rigor of knowledge that has global, rather than merely local validity" (Schoorman, 2000, p. 6).

Higher education institutions may initiate or expand study abroad programs in order to maintain a competitive advantage with other schools: "Suffice 
it to say that institutions and providers are undertaking serious efforts to create an international reputation and name brand for their own institution or for a network/consortium to place them in a more desirable position for competitive advantage" (Knight, 2004, p. 21). Harvard University recently announced that its study abroad efforts need to be expanded (Harvard University Faculty of Arts and Sciences, 2004). As Harvard states these findings publicly, other schools are likely to implement similar institutional measures, if for no other reason than simply to mirror an elite institution. This type of mimetic isomorphism (DiMaggio \& Powell, 1983), or modeling of other institutions when goals and objectives are uncertain, is used by many in the search for institutional competitiveness and legitimacy in international education. ${ }^{11}$

The traditional liberal arts goal of creating global citizens continues to be a relevant rationale for study abroad. However, it is increasingly interwoven with more tangible, bottom-line goals at the institutional and societal levels. This variation, and potential conflict, is demonstrated well by the following contrasting views:

The rationale for the internationalization of undergraduate education must of necessity take us back to the meaning we give to liberal education and liberation of the mind. Whatever our definition might be it is clear that acquiring global awareness and an understanding of the diversity of cultures and societies on our planet has to be considered an integral part of education (Harari, 1992, p. 53).

In this hard-nosed environment, we need to re-think that (idealistic) paradigm and, especially, to identify and explain what the real payoff is for the United States in international education. And today that payoff is economic and social, not idealistic (Trooboff, quoted in Desruisseaux, 1996, p. A45).

Where do nontraditional destinations fit into the schema of varied rationales for study abroad, if they fit at all? The next section attempts to answer these questions.

\section{St ud y A broad Rationales and Nontraditional Destinations}

To answer the question of whether the trend toward nontraditional study abroad destinations is justified, I will examine the rationales presented above in the specific context of nontraditional locations, to determine whether or not 
these destinations assist in achieving the stated goals and objectives, or stand in opposition to them. Ideally, empirical research concerning nontraditional destinations would be brought to bear on such purposes. However, due the paucity of such research, the following section must rely on current policy literature and provide theoretical analyses based on the available information.

Personal growth, global consciousness, and global citizenship are all traditional student-level justifications for embarking on education abroad. Research has shown that diversity experiences in college, of which study abroad trips must be included, increase "openness to diversity" and that it "appears to be particularly the case when interactions with peers occur in situations that provide the potential for encountering new ideas and different people" (Pascarella, 2001, p. 26). If such growth is envisioned as a "stretching" of beliefs, then theoretically a larger stretch may occur when there is greater variation between the ideas and people encountered on a study abroad experience and the student's previous experiences.

There is a normative belief in the study abroad field that an expanded view of the world can be achieved by spending a semester or a year in a foreign country. If this is true, then students who study abroad in countries with greater differences in social and cultural norms as compared to students' homes - i.e., when they are further removed from their comfort zones - may have proportionally greater opportunities for learning and personal growth. There is, of course, the possibility that some students in this context will simply reinforce their negative stereotypes or resort to blaming behaviors similar to those that Jones (2002) reports for service learning. However, with appropriate measures such as "intentionally designed reflection" (Jones, 2002, p. 14), the worldview that could develop from an experience in a country on the periphery of the modern global system will be broader than one formed in a country that holds a position of global power similar to that of the United States. In support of this theory, Harvard University's recent commitment to expanded study abroad "presume[s] that a purposeful mission in a non-Anglophone culture or thirdworld society would instill a higher level of global competency than would a similar experience in Europe or Australia" (Harvard University Faculty of Arts and Sciences, 2004, p. 40).

Other student-centered rationales for study abroad in non-traditional locations relate to personal advantages for employment and improved preparation for the international workforce. Businesses today are becoming more global in order to remain competitive. Companies are trying to gain a foothold with over one billion consumers in China. US corporations are 
outsourcing jobs to India and Latin America to cut cost. Trade agreements are being made and remade within the Americas and with other regional markets. Students that experience nontraditional locations have the potential to gain a greater understanding of the specific issues involved in areas of the world which are more and more valuable in today's global economy. The Whole World Committee, a sub-committee within NAFSA: Association of International Educators, cites further job-related advantages: "Employers can recognize that a different set of skills is developed when living in nontraditional areas. Living in many non-western areas of the world require changes in attitude, flexibility and the development of complex problem solving skills" (The Whole World Committee, 2004).

There are societal dynamics which also lend credibility to the proposed benefits of non-European and non-Australian study abroad experiences. Study in such locations may produce a greater degree of knowledge about the complex, interconnected world in which our own society exists. One example is the recent development of "ecostudents" who study abroad in nontraditional regions of the world to learn about global environmental issues (Woy-Hazelton, 1999). Increased awareness about the dramatic diversity of the world in which we live may also advance ideals common in foreign policy rhetoric, such as "international cooperation." Such vague notions may legitimately be advanced by increasing societal knowledge of all countries in the world, while at the same time allowing foreign societies to learn more about Americans. ${ }^{12}$ Generally speaking, "nontraditional study abroad destinations can reveal the global interconnectedness of problems once thought to be local - from population growth to weapons of mass destruction" (Jenkins, 2002, p. 50).

National security is another societal rationale. Historically, nontraditional countries "account for all the wars in which the US has been engaged since World War II" (Sommer, 2000,p. 64). A greater understanding of nontraditional cultures and countries is therefore vital and is especially critical today as the US engages in the "War on Terror." Students with academic and personal knowledge of the Middle East, the Islamic world, or the Korean peninsula, for example, may be able to improve future policies involving these regions of the world. A security rationale for nontraditional study abroad destinations has been given additional credibility via recent government policies. Provisions included as part of the Intelligence Reform and Terrorism Prevention Act of 2004, on the advice of the 9/11 Commission, call for more person-to-person exchanges with the Muslim regions of the world, and explicitly suggest increased exchange programs with Pakistan and Afghanistan. ${ }^{13}$ 
The goals for study abroad at the societal level appear to be supported by nontraditional locations. This view is summarized by Sommer (2000):

"These are the continents that not only contain the majority of the world's population, but where business and trade opportunities are increasing most dramatically, where the gap between the rich and poor is most alarming and thus most threatening to world peace and security, and where environmental degradation and disease threaten not only the peoples of those continents but, given modern communications and widespread travel, all citizens of the globe" (p. 66).

Support for such beliefs about nontraditional locations is evidenced by possible increases in financial support for study abroad students via federal programs such as the proposed Abraham Lincoln Study Abroad Fellowship program. The Lincoln Fellowships Commission responsible for this anticipated program, based on the vision of the late Senator Paul Simon, has discussed "setting as a goal one million students studying abroad within 10 years, or half the number of those that graduate in a given year" and has also discussed several qualitative goals, one of which may be "achieving substantial numbers studying in destinations other than Western Europe" (M. McCarry, AIEA listserv communication, April 20, 2005).

An institutional rationale is competitiveness with peer institutions. A recent American Council on Education (ACE) study showed that students entering college, as well as their parents, overwhelmingly supported international education. "More than 70 percent considered it important that the institution they attend offer foreign language and international courses, study abroad programs, and opportunities to interact with foreign students" (Hayward \& Siaya, 2001, p. 2). Using the student-as-consumer model in this climate, it is clear that the greater the selection that an institution is able to provide, the more likely it will be to interest potential consumers to purchase their "product." Nontraditional destinations can round out an already broad selection of study abroad offerings or can allow institutions to create niche markets for themselves. ${ }^{14}$

Several of the benefits of nontraditional study abroad destinations examined above (a summary of the potential benefits can be found in Table 1) are summarized succinctly in the following statement:

Given that three-quarters of the world population lives in Asia, Africa, Latin America, and the Middle East, the United States needs a generation of citizens who have first-hand experience of living and learning about these 
tremendously important areas, with their myriad cultures and explosive growth potential. Such experience forms a base upon which to build the new global competencies we need if we are to meet the challenges of an increasingly transnational and global future (Raducha \& Monahan quoted in NAFSA: Association of International Educators, 2004).

The evidence produced by overlaying the literature, policy, and theory concerning nontraditional study abroad destinations onto the rationales used to justify education abroad leads to the following summative proposition: Study abroad experiences in nontraditional destinations are effective instruments for reaching student, societal, and institutional goals of education abroad.

\section{Table 1. Nontraditional Study Abroad Destinations: Benefits}

\begin{tabular}{|c|c|c|}
\hline $\begin{array}{l}\text { Level of } \\
\text { Analysis }\end{array}$ & $\begin{array}{l}\text { Common Rationales for } \\
\text { Study Abroad }\end{array}$ & $\begin{array}{c}\text { Potential Benefits of } \\
\text { Nontraditional Destinations }\end{array}$ \\
\hline Student & $\begin{array}{l}\text { - workforce preparedness } \\
\text { - transnational competence } \\
\text { - global citizenship } \\
\text { - personal growth }\end{array}$ & $\begin{array}{l}\text { - greater understanding of global } \\
\text { economy and employment issues } \\
\text { - greater flexibility } \\
\text { - greater problem solving skills } \\
\text { - improved language skills } \\
\text { - a greater "stretch" of beliefs, values, } \\
\text { and opinions }\end{array}$ \\
\hline Society & $\begin{array}{l}\text { - international and } \\
\text { intercultural understanding } \\
\text { - international cooperation } \\
\text { - national security } \\
\text { - economic advantage }\end{array}$ & $\begin{array}{l}\text { - increased firsthand experience } \\
\text { with global issues and problems } \\
\text { - broader knowledge of critical regions } \\
\text { of the world } \\
\text { - increased societal knowledge } \\
\text { concerning emerging markets } \\
\text { - more globally aware and sensitive } \\
\text { citizenry }\end{array}$ \\
\hline Institution & $\begin{array}{l}\text { - institutional } \\
\text { competitiveness } \\
\text { - marketing potential } \\
\text { - intellectual \& pedagogical } \\
\text { rigor } \\
\text { - increased learning } \\
\text { opportunities }\end{array}$ & $\begin{array}{l}\text { - expanded offerings / increased } \\
\text { competitiveness } \\
\text { - niche market possibilities }\end{array}$ \\
\hline
\end{tabular}




\section{Policy and Research Implications- What $\mathbf{N}$ o w ?}

The last proposition leads to a number of policy implications as well as suggestions for future research. However, this proposition is accompanied by cautions that must be heeded and limitations that must be acknowledged. This analysis has generated a general proposition which, although grounded to the extent possible in existing research, is based largely on policy and theory, as well as the expertise and implied authority of academics, institutions, and professional organizations. This is not an empirical study and can not make definitive claims about the benefits of nontraditional destinations. It has gathered the current evidence and has put forth a reasonable proposition that is in need of further study.

Although tempting to infer, the above proposition does not and should not imply a decrease in the study abroad opportunities for traditional locations. Education abroad to England, Italy, France, Spain, and Australia can and should continue unabated. Increasing the number of students studying in nontraditional locations may instead be part of a larger concerted effort to increase the overall numbers of students studying abroad. After all, "students who study abroad amount to barely more than 1 percent of the 8 million full-time and 5 million part-time undergraduates attending the 3,400 accredited US colleges and universities. Any way you look at it, the number is infinitesimal" (Strategic Task Force on Education Abroad, 2003, p. 7). Rather than implying an increase in the size of the nontraditional slice of the study abroad pie at the expense of the traditional slice, the goal should be to increase the size of the entire pie, thereby allowing nontraditional experiences to grow without decreasing other opportunities.

In response to the above discussion, educators and study abroad professionals may criticize some of the rationales which have been used in the analysis. For example, politically-motivated goals may be temporal and highly contextual, and their true impacts may be difficult to anticipate. Not all in the field agree with education abroad being used reactively as a weapon against terrorism, while other stakeholders may view the traditional, liberal education goals as purely idealistic nostalgia. The objective of presenting these goals comprehensively is not to endorse any in particular, but to test the legitimacy of the nontraditional destination trend against all possible rationales. The resulting proposition, therefore, has increased validity since it is applicable regardless of which underlying motive an individual or an organization utilizes.

Acknowledging the benefits of nontraditional study abroad destinations, institutions may desire to expand their offerings and to encourage more students 
to select such options. This may be a positive development, but deserves caution. An interest in and excitement about nontraditional locations should be accompanied by a thorough organizational needs assessment, and student decisions should always be aided by the advice of a study abroad professional. The "stretch" which may be so effective for personal growth may also be overwhelming or even detrimental to the immature or unprepared student. Encouragement tempered with realism is the necessary recipe.

Once such warnings are acknowledged, this analysis generates policy implications at both the national and institutional levels. For the US government, the dominant policy suggestion is the allocation of more funds for study abroad programs to nontraditional locations. The government already does this to some extent, but the benefits shown in this paper imply that more support is appropriate. A secondary recommendation is to support nontraditional destinations beyond locations that are seen as immediately pertaining to national interests. By supporting a more widespread study abroad program, governmental policy could be more encouraging of cultural, linguistic, and geographical competence.

The primary institutional policy recommendation is also the creation of more opportunities for students to study abroad in nontraditional locations. Toward this end, all types of programs may be utilized, including service learning and internships, and both short- and long-term programs. ${ }^{15}$ Each institution should examine the possibility of offering incentives for students to study in nontraditional locations, perhaps as a way to initiate a new program effectively, but more importantly to achieve the goals of study abroad discussed above. Many organizations are making great strides in this arena, but more creative and widespread efforts can be beneficial for both the institution and education abroad as a whole.

National and institutional policies are unlikely to change substantially without a more considerable body of evidence concerning nontraditional locations. It is for this reason, among others, that more research is necessary. Studies similar to that of the Georgetown Consortium discussed above, are lacking and need to be pursued actively. In support of this attempt, this paper concludes with six sets of suggested research questions from the many that could be derived from this analysis.

1. What are the characteristics of a student who chooses to study abroad in a nontraditional location? Why does the student choose to study in a nontraditional location? Are the rationales discussed above the determinants of their choice? What social, cultural, and/or economic factors affect the selection of a nontraditional destination? 
2. What are the differences between the diversity experienced in a United States classroom and the diversity experienced in a study abroad experience? How do diversity outcomes differ between traditional and nontraditional locations? How do these differences affect cognitive and psycho-social learning outcomes?

3. How can researchers categorize the degree of cultural difference in study abroad destinations? Attempts to quantify this construct in a consistent manner would assist future research efforts to determine the worth of nontraditional locations.

4. How do nontraditional destinations affect "traditional" study abroad outcomes? Proposed outcomes such as openness to diversity and intercultural sensitivity should be assessed for nontraditional versus traditional locations. Toward this end, existing assessment tools may be utilized more effectively, such as the Intercultural Development Inventory (IDI). ${ }^{16}$

5. How do nontraditional destinations impact students in the long term? Longitudinal studies of study abroad students could control for background characteristics and manage self-selection issues, thereby determining the association of nontraditional destinations with careers, life choices, etc.

6. Do the impacts of other factors commonly examined in study abroad research differ between traditional and nontraditional locations? For example, do the effects of short- and long-term programs differ by location-type? Do the effects of living with a family or with other students differ by location-type? Do the effects of learning in the local language or in English differ by location-type?

\section{Conclusion}

This analysis has utilized existing literature, policy, and theory to establish the role that nontraditional study abroad destinations play in education abroad. Regardless of the specific rationales utilized, nontraditional destinations appear able to help individuals, society, and institutions to meet their goals for education abroad. Policies to support this finding should be considered by both educational and governmental organizations. A widespread and interdisciplinary research effort should also examine this proposition more fully either to support or invalidate the benefits which have been posited. 


\section{Notes}

${ }^{1}$ I would like to thank Dr. Mick Vande Berg, Tricia Seifert, Susan Wells, and the anonymous referees for their helpful and insightful comments on previous drafts of this paper.

${ }^{2}$ For the purposes of this paper, "education abroad" and "study abroad" will be used synonymously.

${ }^{3}$ The exclusion of Eastern Europe as a nontraditional destination has some limitations. Several of the countries in this region do not yet draw many American students, and therefore could be considered nontraditional. However, due to the popularity of a few Eastern European nations as destinations, and due to the European Union which presents all of Europe as a more unified whole, Europe will be considered as one region, and will be considered a traditional destination.

"Terminology such as "third world" is no longer in vogue. Even the term "developing country" often implies a broader meaning that simply an economy which is not as developed as the most industrialized. Instead, it may be viewed as a value judgment, implicitly stating that the "developed" countries are better in some general sense of the word. For this reason, I avoid using this classification.

${ }^{5}$ This definition may categorize some Eastern European countries that have very few American study abroad students as "traditional" rather than "nontraditional." This is acknowledged as a minor limitation of this definition.

${ }^{6}$ Although not European, Australia is a traditional destination as well, and ranked fifth for 2003-2003.

${ }^{7}$ Eastern Europe participation numbers, which may be considered nontraditional in some frameworks, were up 21\% in 2002-2003.

${ }^{8}$ In light of more recent global trends, she also adds additional groupings to capture rationales at the national and institutional levels (Knight, 2004).

${ }^{9}$ Language learning is one feature of study abroad has been examined in several studies (for a recent example, see Segalowitz et al., 2004).

${ }^{10}$ These viewpoints are grounded in the spirit of critical pedagogy (Apple, 1979; Aronowitz \& Giroux, 1985; Giroux \& McLaren, 1989).

${ }^{11}$ For a further discussion of isomorphism in international education, see Wells \& Henkin (2005).

${ }^{12}$ Governmental endorsement of this general philosophy is evident via the final two of the three goals of the United States Peace Corps: "Helping promote a better understanding of Americans on the part of the peoples served" and "Helping promote a better understanding of other peoples on the part of all Americans." 
Frontiers: The Interdisciplinary Journal of Study Abroad

${ }^{13}$ Rationales derived from the "War on Terror," as well as other government policies, are temporal and therefore inherently risky to base a judgment on. Nevertheless, they serve as examples of the far-reaching ways in which nontraditional education abroad may be justified.

${ }^{14}$ This niche market approach may also serve as a benefit to the diversity of higher education in general (Birnbaum, 1983).

${ }^{15}$ The policy suggestion for all types of study abroad programs is not a claim that each type of program has equal value for student, societal, or institutional goals.

${ }^{16}$ The IDI is based on the Development Model of Intercultural Sensitivity (DMIS) (Bennett, 1986, 1993; Hammer, Bennett, \& Wiseman, 2003). 


\section{$R$ ef e r e n c e s}

American Council on Education (ACE), \& American Association of University Professors (AAUP). (2000). Does diversity make a difference? Three research studies on diversity in college classrooms. Washington D.C.: American Council on Education (ACE) and American Association of University Professors (AAUP).

Apple, M. W. (1979). Ideology and curriculum. London: Routledge \& K. Paul.

Aronowitz, S., \& Giroux, H. A. (1985). Education under siege: The conservative, liberal, and radical debate over schooling. South Hadley: Bergin \& Garvey.

Arum, S., \& Van de Water, J. (1992). The need for a definition of international education in us universities. In C. B. Klasek (Ed.), Bridges to the future: Strategies for internationalizing higher education (pp. 191-203). Washington D.C: Association of International Education Administrators.

Bennett, M. J. (1986). Towards ethnorelativism: A developmental model of intercultural sensitivity. In R. M. Paige (Ed.), Cross-cultural orientation: New conceptualizations and applications (pp. 27-70). New York: University Press of America.

Bennett, M. J. (1993). Towards ethnorelativism: A developmental model of intercultural sensitivity. In M. Paige (Ed.), Education for the intercultural experience. Yarmouth, ME: Intercultural Press.

Biddle, S. (2002). Internationalization: Rbetoric or reality? (ACLS Occasional Paper, No.56). New York: American Council of Learned Societies.

Birnbaum, R. (1983). Maintaining diversity in higher education (1st ed.). San Francisco: Jossey-Bass.

Bond, M. L., \& Jones, M. E. (1994). Short-term cultural immersion in Mexico. Nursing and Health Care, 15(5), 248-253.

Bourdieu, P. (1985). The forms of capital. In J. G. Richardson (Ed.), Handbook of theory and research for the sociology of education (pp. 241-258). New York: Greenwood.

Coleman, J. S. (1988). Social capital in the creation of human capital. American Journal of Sociology, 94, S95-S121.

Cook, L. A. (2004). The relationship between expectation-experience growth discrepancies and satisfaction among students participating in international service-learning programs. Dissertation Abstracts International. 65(03), 847A. Retrieved May 9, 2005, from http://proquest.umi.com

Council on International Educational Exchange. (2004). Principles of good practice for international education. Retrieved December 15, 2004, from http://www.ciee.org/about/educational_priniciples.aspx 
Desruisseaux, P. (1996). New us law makes foreign students, scholars feel unwelcome. The Chronicle of Higher Education, Nov. 29, A45.

Desruisseaux, P. (1999). 1.5\% rise in American students abroad shows popularity of non-European destinations. Chronicle of Higher Education, 46(16), A60-A61.

DiMaggio, P. J., \& Powell, W. W. (1983). The iron cage revisited: Institutional isomorphism and collective rationality in organizational fields. American Sociological Review, 48(2), 147-160.

Elkin, P. L. (1998). Tonderai: Studying abroad in Zimbabwe. Fort Bragg, CA: Lost Coast Press.

Farrell, P., \& Suvedi, M. (2003). Studying abroad in Nepal: Assessing impact. Frontiers: The Interdisciplinary Journal of Study Abroad, IX, 175-188.

Fraser, S. E., \& Brickman, W. W. (1968). A bistory of comparative and international education: Nineteenth century documents. Glenview, IL: Scott Foresman.

Giroux, H. A., \& McLaren, P. (Eds.). (1989). Critical pedagogy, the state, and cultural struggle. Albany: State University of New York Press.

Gurin, P., Dey, E. L., Hurtado, S., \& Gurin, G. (2002). Diversity and higher education: Theory and impact on educational outcomes. Harvard Educational Review, 72(3), 330-367.

Gurin, P., Nagda, B. A., \& Lopez, G. E. (2004). The benefits of diversity in education for democratic citizenship. Journal of Social Issues, 60(1), 17.

Hammer, M. R., Bennett, M. J., \& Wiseman, R. (2003). Measuring intercultural sensitivity: The intercultural development inventory. International Journal of Intercultural Relations, 27(4), 421-444.

Hansen, H. M. (2002). Defining international education. New Directions for Higher Education, 2002(117), 5-12.

Harari, M. (1992). The internationalization of curriculum. In C. B. Klasek (Ed.), Bridges to the future: Strategies for internationalizing higher education (pp. 52-79). Washington D.C.: Association of International Education Administrators.

Harvard University Faculty of Arts and Sciences. (2004). A report on the Harvard college curricular review. Cambridge, MA: Harvard University.

Hawkins, J. N., \& Cummings, W. K. (Eds.). (2000). Transnational competence: Rethinking the US-Japan educational relationship. Albany, NY: State University of New York Press.

Hayward, F., \& Siaya, L. (2001). Public experience, attitudes, and knowledge: A report on two national surveys about international education. Washington D.C: American Council on Education. 
Hutchins, M. M. (1996). International education study tours abroad: Students' professional growth and personal development in relation to international, global, and intercultural perspectives. Dissertation Abstracts International. 57(10), 4235A. Retrieved May 9, 2005, from http://proquest.umi.com

Inglis, A., Rolls, C., \& Kristy, S. (1998). The impact of participation in a study abroad programme on students' conceptual understanding of community health nursing in a developing country. Journal of Advanced Nursing, 28, 911-917.

Institute of International Education. (2004). Open doors: Report on international educational exchange. Retrieved November 26, 2004, from http://opendoors.iienetwork.org/

Jenkins, K. (2002). Off the beaten path. Black Issues in Higher Education, 19(6), 50.

Jones, S. R. (2002). The underside of service learning. About Campus, 7(4), 10-15.

Knight, J. (2003). Updated internationalization definition. International Higher Education, (33), 2-3. Retrieved, from http://www.bc.edu/bc_org/avp/ soe/cihe/newsletter/News33/Newslet33.htm

Knight, J. (2004). Internationalization remodeled: Definition, approaches, and rationales. Journal of Studies in International Education, 8(1), 5-31.

Martin, J. N., Bradford, L., \& Rohrlich, B. (1995). Comparing predeparture expectations and post-sojourn reports: A longitudinal study of U.S. Students abroad. International Journal of Intercultural Relations, 19(1), 87-110.

Martin, J. N., \& Rohrlich, B. (1991). The relationship between study-abroad student expectations and selected student characteristics. Journal of College Student Development, 32(1), 39-46.

Mestenhauser, J. (1998). The US in international education; what kind of partnership? The Journal of International Education, 9(2), 44-52.

Mizuno, N. (1999). The impact of study abroad experience on American college students who studied in Japan. Dissertation Abstracts International. 59(08), 2826A. Retrieved May 9, 2005, from http://proquest.umi.com

NAFSA: Association of International Educators. (2004). Advising for whole world study. Retrieved December 14, 2004, from http://www.secussa. nafsa.org/guide/study.html

Pascarella, E. T. (2001). Cognitive growth in college: Surprising and reassuring findings from the national study of student learning. Change, November/ December, 21-27.

Racette, D. (1996). Study abroad in the non-industrial world: Problems and potentials. The International Review, 6, 31-41. 
Rohrlich, B., \& Martin, J. N. (1991). Host country and reentry adjustment of student sojourners. International Journal of Intercultural Relations, 15(2), 163-182.

Rubin, A. M. (1995). U.S. Enrollment in study-abroad programs grows as more students head for developing nations. Chronicle of Higher Education, 42(11), A40-41.

Saltzman, A., \& Mulrine, A. (1996, April 8). Roads less traveled. U.S. News E World Report, 120, 57-59.

Sampson, D. L., \& Smith, H. P. (1957). A scale to measure world-minded attitudes. Journal of Social Psychology, 45, 99-106.

Schechter, M. (1993). Internationalizing the curriculum and building bridges across disciplines. In S. Cavusgil (Ed.), Internationalizing business education (pp. 129-140). East Lansing, MI: Michigan State University.

Schoorman, D. (2000). What really do we mean by 'internationalization?' Contemporary Education, 71(4), 5-12.

Segalowitz, N., Freed, B., Collentine, J., Lafford, B., Lazar, N., \& Diaz-Campos, M. (2004). A comparison of Spanish second language acquisition in two different learning contexts: Study abroad and the domestic classroom. Frontiers: The Interdisciplinary Journal of Study Abroad, X, 1-18.

Siaya, L., \& Hayward, F. (2003). Mapping internationalization on us campuses: Final report. Washington D.C.: American Council on Education.

Sommer, J. G. (2000). Education abroad (SIT Occasional Paper). Brattleboro, VT: School for International Training (SIT).

Strategic Task Force on Education Abroad. (2003). Securing America's future: Global education for a global age (Report). Washington D.C.: NAFSA: Association of International Educators.

Sutton, R. C., \& Rubin, D. L. (2004). The GLOSSARI project: Initial findings from a system-wide research initiative on study abroad learning outcomes. Frontiers: The Interdisciplinary Journal of Study Abroad, X, 65-82.

The Whole World Committee. (2004). FAQs for students. Retrieved December 13, from http://www.secussa.nafsa.org/wwc-studentfaq.html

Vande Berg, M., Balkcum, A., Scheid, M., \& Whalen, B. J. (2004). The Georgetown university consortium project: A report at the halfway mark. Frontiers: The Interdisciplinary Journal of Study Abroad, X, 101-116.

Wells, R., \& Henkin, A. (f2005). Isomorphism in international education. International Journal of Educational Reform 14(3), pp.280-293.

Woy-Hazelton, S. (1999). Ecostudents: The new wave of students abroad. Social Education, 63(2), 89-90. 